\title{
PROSES QUENCHING DAN TEMPERING \\ PADA SCMnCr2 UNTUK MEMENUHI \\ STANDAR JIS G 5111
}

\author{
Agung Setyo Darmawan \\ Teknik Mesin Universitas Muhammadiyah Surakarta \\ Jl. A. Yani Tromol Pos I Pabelan Kartasura \\ agungsetyod@yahoo.com
}

\begin{abstract}
ABSTRAK
Baja SCMnCr produksi PT. Baja Kurnia Klaten mempunyai harga kekerasan $210.8 \mathrm{H}_{B}$ dan kekuatan tarik 539.21 N/mm². Baja produksi PT. Baja Kurnia Klaten ini belum memenuhi standar JIS G 5111 untuk Baja SCMnCr. Oleh karena itu dilakukan proses quenching yang dilanjutkan dengan proses tempering pada baja SCMnCr2 untuk memenuhi standar tersebut. Proses quenching dilakukan dengan temperatur austenitisasi $850{ }^{\circ} \mathrm{C}$. Proses tempering dilakukan dengan temperatur penahanan $600{ }^{\circ} \mathrm{C}$ dan variasi waktu penahanan 20, 30, dan 45 menit. Sesudah dilakukan proses heat treatment, Baja SCMnCr2 diuji strukturmikro, kekerasan, dan kekuatan tariknya. Foto struktur mikro baja SCMnCr2 setelah diquenching dan kemudian ditempering memperlihatkan fasa ferit dan martensit temper. Setelah dilakukan quenching dan tempering, harga kekerasan untuk waktu penahanan 20, 30, dan 45 menit adalah 298.6 $H_{B}, 285 H_{B}$, dan $254.7 H_{B}$ dan harga kekuatan tarik untuk waktu penahanan 20, 30, dan 45 menit adalah $931.73 \mathrm{~N} / \mathrm{mm}^{2}, 846.54 \mathrm{~N} /$ $\mathrm{mm}^{2}$, dan $878.18 \mathrm{~N} / \mathrm{mm}^{2}$. Harga kekerasan dan kekuatan ini sudah memenuhi standar JIS G 5111. Kenaikan harga kekerasan dari sebelum ke sesudah proses heat treatment disebabkan oleh terbentuknya fasa martensit temper. Sementara, penurunan kekerasan akibat waktu penahanan tempering yang semakin lama disebabkan oleh membesar dan semakin banyaknya fasa ferit.
\end{abstract}

Kata Kunci: SCMnCr2, quenching, tempering, JIS G 5111

\section{PENDAHULUAN}

Baja banyak digunakan dalam bidang teknik. Salah satu keuntungan pemakaian baja adalah karena sifat mekaniknya yang mempunyai rentang cukup lebar yang dapat disesuaikan dengan kegunaannya. Pemakaian baja dalam kehidupan masyarakat dan dunia industri mensyaratkan faktor sifat mekanik tertentu yang sesuai dengan standar. JIS (Japanese Industrial Standard) adalah salah satu dari beberapa macam standarisasi di dunia. JIS sendiri dikeluarkan oleh negara Jepang sebagai salah satu acuan dalam dunia teknik. Standarisasi ini digunakan agar produk baja dapat digunakan secara aman.

Sifat mekanik, sebagai contoh, kekuatan tarik dipengaruhi oleh ukuran butir. Perlakuan Panas (Heat treatment) dapat digunakan untuk mengatur ukuran butir dan meningkatkan sifat mekanik material [Anderson, 2003].). Definisi perlakuan panas adalah pengubahan struktur- 
mikro, dengan memberikan pemanasan dan mengatur laju pendinginan sehingga diperoleh strukturmikro yang diinginkan. Yang tidak berubah pada proses perlakuan panas ini adalah komposisi bahan. Sedang definisi strukturmikro sendiri adalah konfigurasi distribusi fasa untuk suatu komposisi tertentu.

Contoh proses perlakuan panas adalah full anealling, normalizing, quenching dan tempering. Pada full anealling dan normalizing baja karbon, semakin cepat laju pendinginan, semakin kecil butir yang terjadi [Callister Jr., 2007]. Sementara quenching akan mengakibatkan terbentuknya fasa martensit yang kuat, keras, dan getas, yang akan dapat ditingkatkan ketangguhannya dengan proses tempering.

Full anneal adalah pemanasan baja ke temperatur $30^{\circ} \mathrm{C}$ diatas garis $\mathrm{A}_{3}$ atau $\mathrm{A}_{1}$ (tergantung pada kandungan karbon), ditahan pada temperatur tersebut untuk mendapatkan fasa austenit yang homogen, kemudian didinginkan secara lambat pada tungku. Hasil unluk baja hypoeutectoid adalah perubahan fasa dari austenit ke perlit lamellar kasar (butir besar) vang lunak, bebas tegangan, dan ferit yang halus. Kata pelunakan (annealing) saja jika digunakan pada paduan besi $(\mathrm{Fe})$ menunjukkan proses full anneal. Jika digunakan pada paduan non besi kata pelunakan (annealing) menyatakan perlakuan panas yang dirancang untuk melunakkan struktur hasil pengerjaan dingin dengan rekristalisasi dan atau kemudian pertumbuhan butir.

Karena memerlukan waktu yang lama dan mahal, dalam beberapa kasus full anneal diganti dengan normalizing. Pada normalizing, pendinginan dilakukan di udara (laju pendinginan lebib cepat dibandingkan ditungku) dan menghasilkan struktur perlit yang halus. Baja di normalizing untuk mendapatkan kekerasan dan kekuatan yang lebih besar dibanding jika dengan full anneal.

Menurut Widyatmadji (2001), perlakuan panas normalizing memberikan perubahan terhadap struktur mikro dan kekuatan baja. Makin tinggi temperatur austenisasi dan makin lama waktu tahan, kekuatan baja makin menurun, namun ketangguhannya akan meningkat.
Tempering pada baja dilakukan dengan memanaskannya pada temperatur sedikit $723^{\circ} \mathrm{C}$. Perlakuan panas ini umumnya dilakukan setelah proses celup cepat (quenching). Tujuan dari tempering adalah untuk mendapatkan baja yang lebih tangguh (tough) dan juga liat (ductile) tanpa banyak mengurangi kekuatan (strength).

Ketahanan aus besi cor liat feritik berdasarkan penelitian Sahin (2008) berkurang setelah mengalami proses tempering pada temperatur $500^{\circ} \mathrm{C}$ dengan waktu penahanan 1 dan 5 jam.

Mulyanti (1996) meneliti pengaruh perlakuan panas pada paduan baja mangan austenit dimana kekerasan akan turun dan harga impak akan naik jika dilakukan proses temper, disebutkan juga bahwa dengan naiknya temperatur austenitisasi, maka kekerasan akan turun dan harga impak akan naik.

Glownia (2008) melakukan penelitian pengaruh pemaduan mikro terhadap keoptimalan proses tempering. Keoptimalan proses tempering dapat dinaikkan dengan presipitasi karbonnitrida.

Usaha untuk memenuhi standar JIS G 5111 pada baja cor SCMnCr2 produksi PT. Baja Kurnia Klaten telah dilakukan oleh Darmawan dkk. (2008). Pengujian kekuatan pada raw material baja ini memperlihatkan hasil di bawah standar yaitu kekuatan tariknya 539.21 $\mathrm{N} / \mathrm{mm}^{2}$. Oleh karena itu dilakukan proses normalizing dan tempering pada baja SCMnCr2 untuk memenuhi standar tersebut. Sesudah dilakukan proses heat treatment Baja SCMnCr2 diuji strukturmikro dan kekuatan tariknya. Foto struktur mikro baja SCMnCr2 setelah dinormalizing dan kemudian ditempering memperlihatkan butir yang lebih kecil dibanding raw materialnya.. Setelah dilakukan normalizing dan tempering harga kekuatan naik menjadi $685.51 \mathrm{~N} /$ $\mathrm{mm} 2$ dan akan menurun menjadi $664.21 \mathrm{~N} / \mathrm{mm}^{2}$ ketika waktu penahanan tempering diperlama menjadi 45 menit. Hal ini disebabkan karena meningkatnya ukuran butir ferit dan perlit. 

Garis DE = Proses pemanasan hingga tem- peratur 600Ú C.
Garis EF = Proses penahanan pada tempe- ratur (a) selama 20 menit untuk specimen A(b) selama 30 menit untuk specimen B (c) selama 45 menit untuk specimen $\mathrm{C}$.
Garis FG = Proses pendinginan dengan udara sampai temperatur kamar di udara terbuka.

\section{HASIL DAN PEMBAHASAN}

\section{Hasil dan Analisa Data Hasil Pengujian Struktur Mikro.}

Struktur mikro ini dilihat dengan Olympus Metallurgical Microscopes dengan pembesaran 200 kali, dari pemotretan dengan kamera didapatkan gambar 3, 4 ,5 dan 6 .

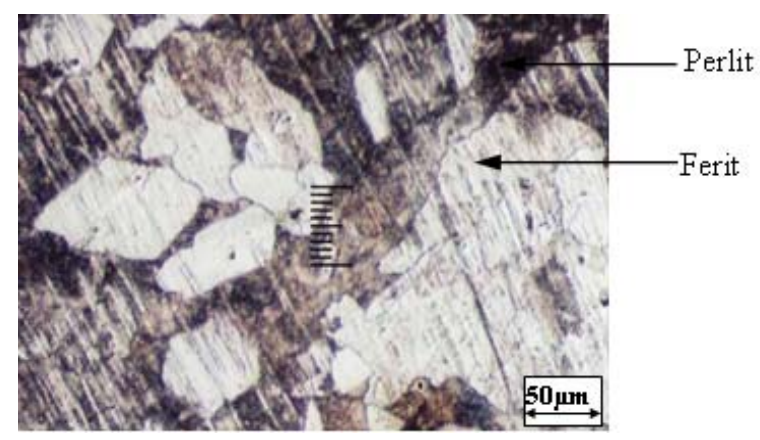

\section{Gambar 3. Struktur Mikro dari Raw Material}

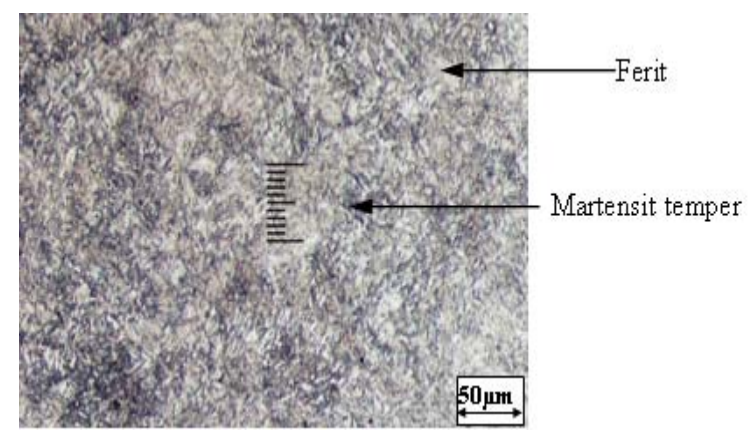

\section{Gambar 4. Struktur Mikro dari Specimen A}

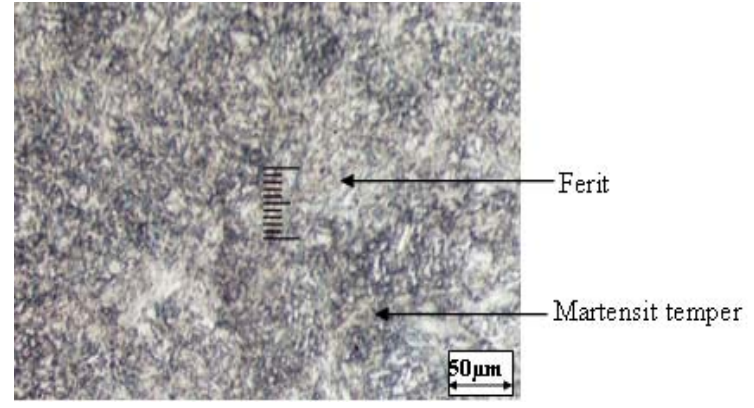

\section{Gambar 5. Struktur Mikro dari Specimen B}

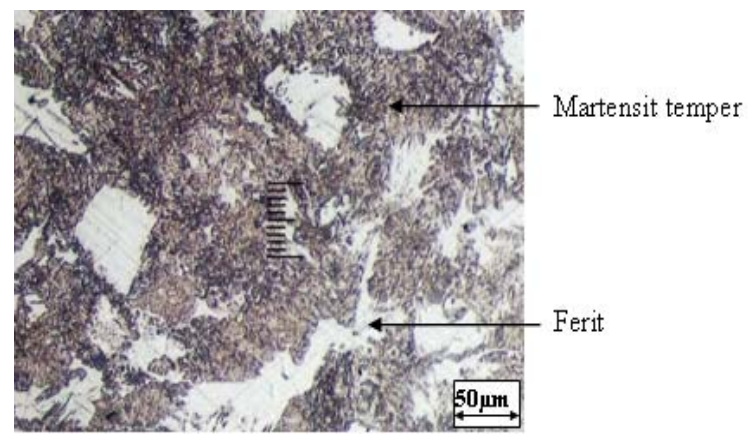

\section{Gambar 6. Struktur Mikro dari Specimen C}

Raw material mempunyai struktur mikro yang terdiri dari fasa ferit dan perlit (gambar 3). Fasa ini akan bertransformasi menjadi ferit dan martensit temper setelah mengalami proses quenching dan tempering, dimana jika waktu penahanan tempering lebih panjang, maka butir yang terjadi akan lebih besar (Gambar 4-6).

\section{Hasil dan Analisa Data Hasil Pengujian Kekuatan Tarik}

Kekuatan tarik untuk baja SCMnCr2 berdasarkan standar JIS G5111 adalah minimum $590 \mathrm{kgf} / \mathrm{mm}^{2}$. Diagram alir tegangan-regangan teknik hasil pengujian tarik di perlihatkan pada gambar 7. Tabel 1 memperlihatkan data kekuatan tarik dan kekuatan luluh. Gambar 8 memperlihatkan perbandingan kekuatan tarik maksimum dari ScMnCr2 sebelum dan sesudah proses treatment. 
Tabel 1. Data Hasil Uji Tarik Bahan ScMnCr2 Sebelum dan Sesudah Proses Treatmen.

\begin{tabular}{|c|c|c|}
\hline Spesimen & $\begin{array}{c}\text { Kekuatan } \\
\text { Luluh } \\
\left(\mathrm{N} / \mathbf{m m}^{2}\right)\end{array}$ & $\begin{array}{c}\text { Kekuatan } \\
\text { Tarik } \\
\left(\mathbf{N} / \mathbf{m m}^{2}\right)\end{array}$ \\
\hline $\mathrm{RM}$ & 434.44 & 539.21 \\
\hline A & 827.07 & 931.73 \\
\hline B & 734.35 & 846.54 \\
\hline C & 745.44 & 878.18 \\
\hline
\end{tabular}

Keterangan:

RM : Raw Material

A : Spesimen Treatment Temperatur Austenitisasi $850^{\circ} \mathrm{C}$ Quenching + Temper $600^{\circ} \mathrm{C}$ 20 menit

B : Spesimen Treatment Temperatur Austenitisasi $850^{\circ} \mathrm{C}$ Quenching + Temper $600^{\circ} \mathrm{C}$ 30 menit

C : Spesimen Treatment Temperatur Austenitisasi $850^{\circ} \mathrm{C}$ Quenching + Temper $600^{\circ} \mathrm{C}$ 45 menit

Grafik Tegangan - Regangan

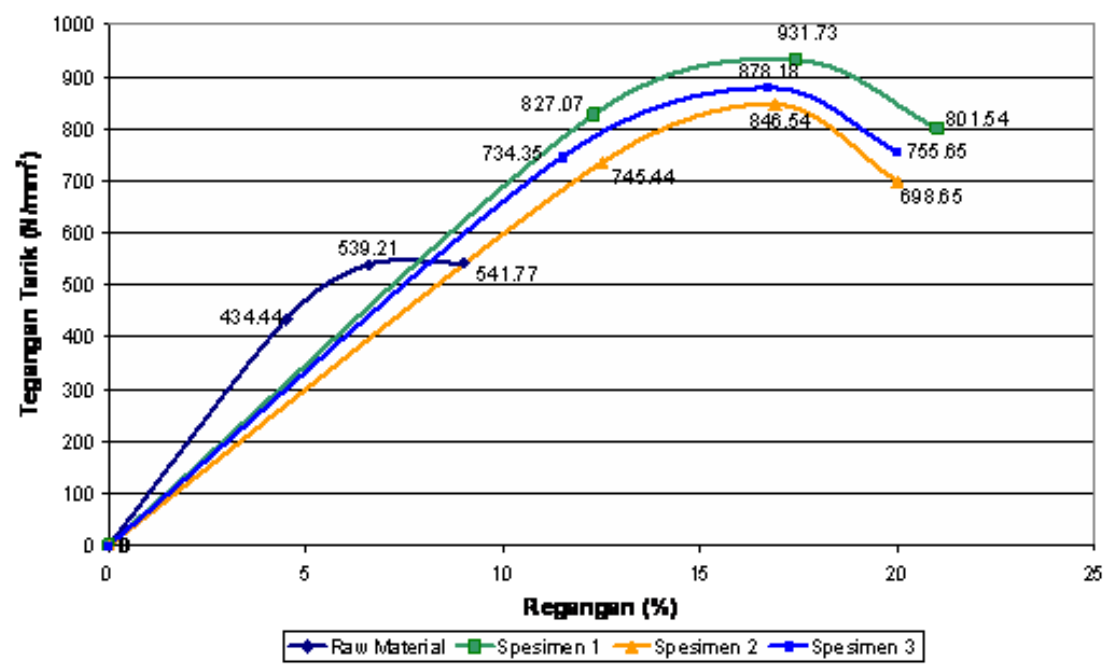

Gambar 7. Diagram Alir Tegangan-Regangan Teknik Hasil Pengujian Tarik

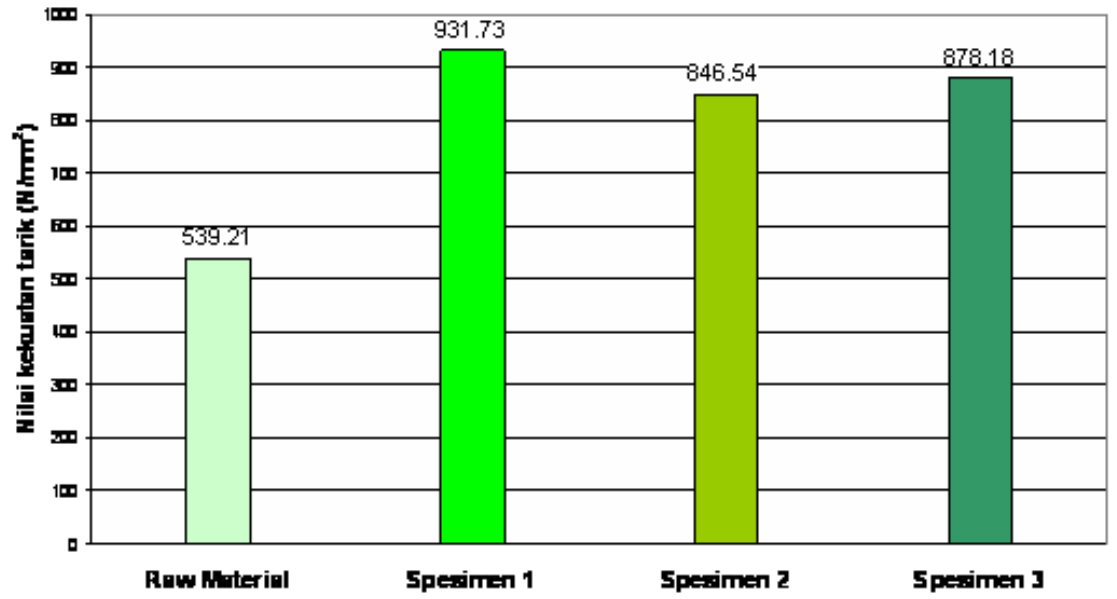

Gambar 8. Perbandingan Kekuatan Tarik Sebelum dan Sesudah Proses Heat Treatment 
Kekuatan tarik bahan setelah di heat treatment mengalami peningkatan, semakin lama waktu penahanan, kekuatan akan cenderung menurun karena butir membesar. Proses ini masih memperlihatkan bahwa proses heat treatment yang digunakan berhasil mengubah harga kekuatan sehingga memenuhi standar JIS G5111.

\section{Hasil dan Analisa Data Hasil Pengujian Kekerasan}

Standar JIS G 5111 mensyaratkan kekerasan minimum baja $S C M n C r 2$ adalah 183 BHN. Hasil pengujian kekerasan diperlihatkan pada Gambar 9.

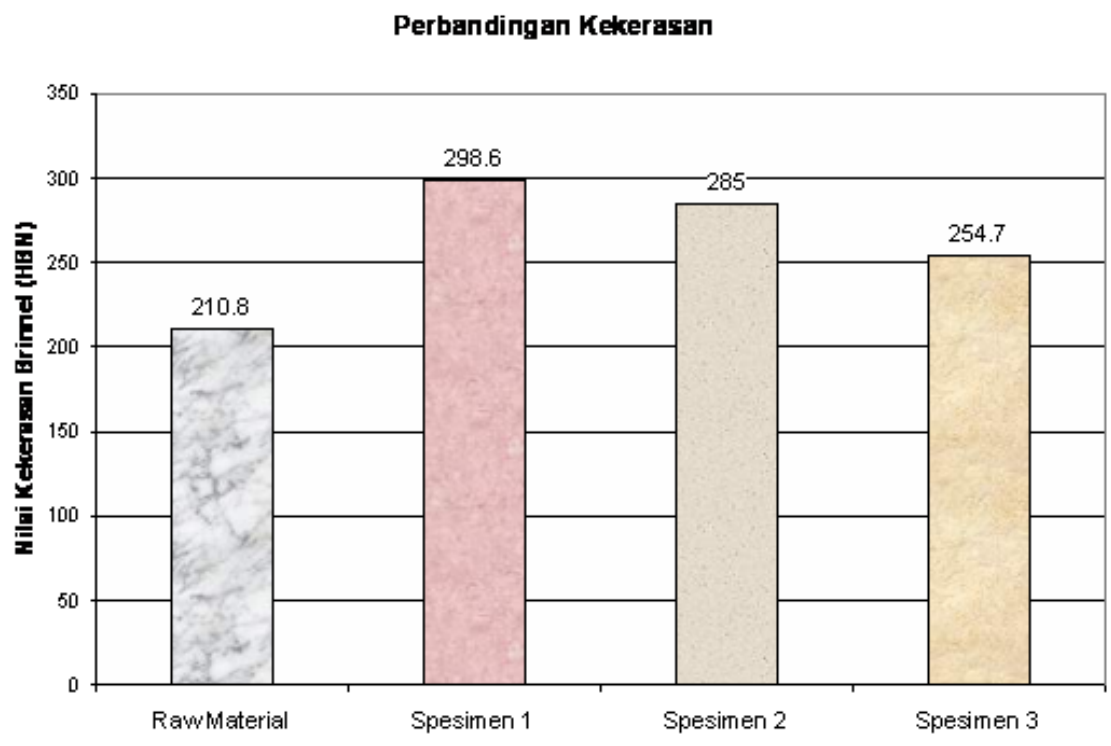

Gambar 9. Grafik Kekerasan Rata-Rata (BHN)

Kekerasan setelah proses heat treatmen memperlihatkan kenaikan. Meskipundemikian,jika waktu penahanan diperpanjang kekerasan akan turun, karena butir membesar. Kekerasan hasil proses heat treatmentini memenuhi standar JIS G5111.

\section{KESIMPULAN}

Dari hasil pengujian kekuatan tarik dan kekerasan, proses quenching yang diikuti proses tempering dengan waktu penahanan sampai 45 menit berhasil memenuhi standar JIS G 5111.

\section{PERSANTUNAN}

Penulis mengucapkan terima kasih atas bantuan Dwi Setiawan Piyarto terhadap penelitianini.

\section{DAFTAR PUSTAKA}

Anderson, J.C., 2003, Material Science for Engineers, Nelson Thornes, Cheltenham.

Callister, Jr., William D., 2007, Materials Science and Enginering; An Introduction, John Wiley \& Sons, New York 
Darmawan, A.S., Masyrukan, Ariyandi, R., 2007, Proses Quenching Dan Tempering Pada SCMnCr2 Untuk Memenuhi Standar JIS G 5111, Media Mesin ISSN 1411-4348, Teknik Mesin UMS, Surakarta.

G³0wnia, J., Kalandyk, J. B., 2008, Effect of Precipitation strengthening in low alloyed Mn-Ni cast steel, Journal of Materials Processing Technology, Volume 207, Issues 1-3, Pages 147-153.

Mulyanti, 1996, Pengaruh Kadar Mangan (Mn) Dan Perlakuan Panas Terhadap Sifat Mekanis Dan Struktur Mikro Paduan Baja Mangan Austenit, UI Jakarta.

Sahin, Y., Erdogan, M., Cerah, M., 2008, Effect of martensite volume fraction and tempering time on abrasive wear of ferritic ductile iron with dual matrix, Wear, Volume 265, Issues 1-2, Pages 196-202.

Widyatmadji, 2001, Pengaruh Perlakuan Panas Normalisasi Terhadap Sifat Mekanik Dan Struktur Mikro Baja 1K3816AT Untuk Aplikasi Casing \& Tubing Spesifikasi API 5CT K55, UI, Jakarta. 